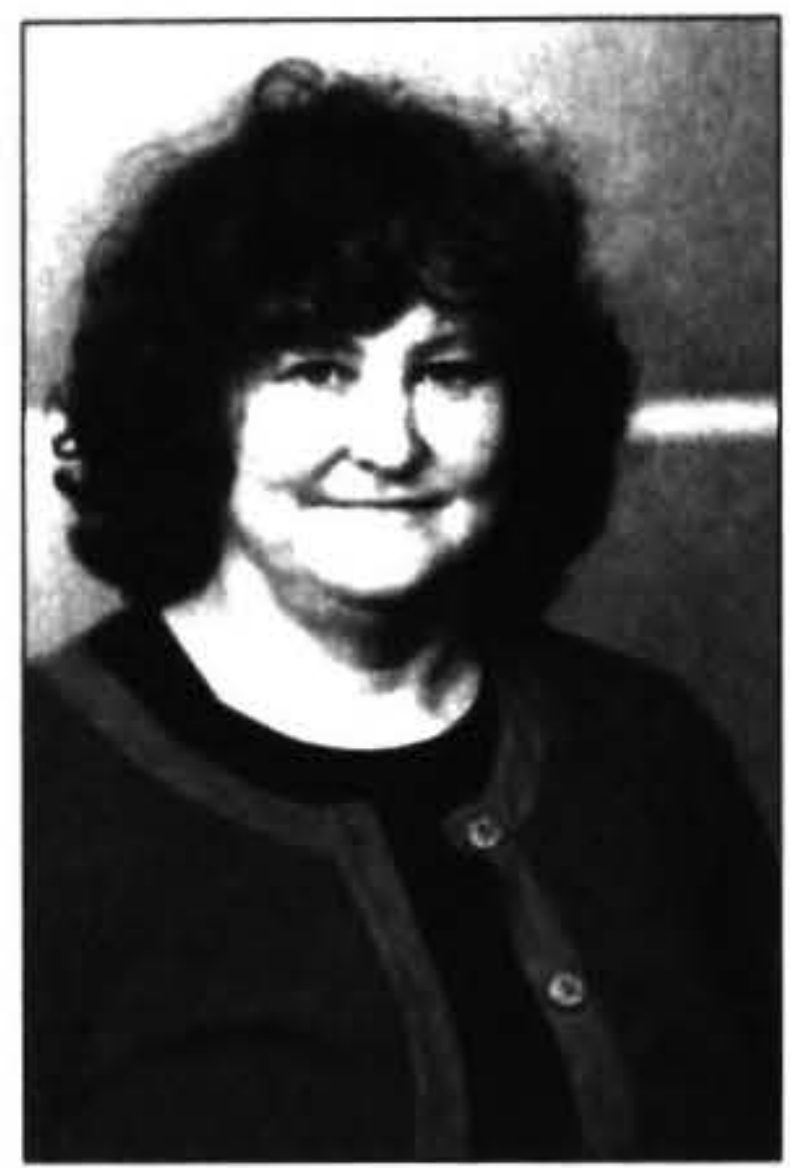

\title{
THE ROLE OF MANAGERS IN \\ WORK-LIFE BALANCE \\ IMPLEMENTATION
}

\author{
Mervyl McPherson \\ Equal Employment Opportunities Trust. \\ Auckland
}

\begin{abstract}
The paper drans on existing overseas research to present an argument for the importance of the role of individual managers and workplace culture in the successful outcome of work-life halance programmes in workplaces. Using findings from a recent Work-Life Surver of New Zealand employers hy the EEO Trust, and other New Zealand based research. it looks at where New Zealand organisations are at in terms of the role of managers in implementing worklife halance programmes. Additional information fiom employees perspectives on the role of managers in the implementation of work-life balance programmes is drawn from a qualitative stucty of mothers experience of combining paid work and parenting carried out hy the author for the Families Commission (forthcoming) and other New Zealand research. The paper concludes with suggestions of how New Zealand organisations can improve outcomes from work-life halance initiatives hi greater attention to the role of managers in the process.
\end{abstract}

\section{Introduction}

The availability of work-life policies does not necessarily result in uptake by employees, reduced work-life conflict and enhanced performance. retention and redued absentecism (Bond. 2004: Hudson. 2005: McDonald et al. 2005: O.Driscoll et al. 2003)

Uptake and reduction in work-life conflict is related to organizational environment workplace culture (Hudson, 2005: Bond, 2004: Thompson et al. 1999: Thompson and Prottas, 2006). McDonald. Brown and Bradley (2005) identified five dimensions of organizational work-life culture that account for the gap between policy and practice in Australia: lack of managerial support. perceived career consequences, time expectations. gendered pereeptions of utilization of work-life provisions, and co-worker support. Bond (2004) notes that while the concept of work-family culture has been operationalised in different ways, some measure of supportiveness within organizations is a consistent factor. with supervisor/managerial support being one aspect of that. This paper focuses on the role of managerial support.

Work-life balance is defined on the New Zealand Department of Labour work-life balance website as being about "effectively managing the juggling act between paid work and the other activities that are important to people" (http:/www.dol.govt.nz/worklife/whatis.asp).

They note that it is not about saying work is wrong or bad, but that "it shouldn't crowd out the other things that matter to people, like time with family, participation in community activities, voluntary work. personal development, leisure and recreation". They also point out that there is no "one size fits all solution". The "right' balance is a very personal thing that differs for different people and at different stages of the life course.

The term "work" is being used here to refer to paid work or employment. The term "work-life balance" is a contested term, with many alternatives suggested, such as "work-life integration", "work-life interface", "work-life mosaic", "work-life reconciliation" or "work-life coordination" (McPherson, 2007). While many argue with the use of the term work-life balance, mainly on the basis that it may be interpreted as work not being a part of life, or that balance is not the aim of some but rather integration, arguing that the two cannot be compartmentalised and separated, others dislike the term integration as they want separation and boundaries between their work life and the rest of their life. While the terminology is debated by academics, work-life balance is the terminology in popular usage in both social and human resource management literature and the popular media.

Work-life initiatives investigated in the EEO Trust WorkLife Survey, in order of frequency of provision by employers, were domestic/special leave, flexible work hours, discouraging long hours, study leave/career break, support for carers, family oriented social events, flexible work location, transition between full and part-time work in same position, children welcome at work, providing information on work-life balance, job sharing, part-time work at senior levels, fridge for storing breast milk, on site breastfeeding room/area, compressed working week, term-time working. school holiday and after-school programmes or subsidies, childcare facilities or subsidies, 
and having a health and wellness programme (EEO Trust, 2006).

\section{The Relationship Between Work-Life Balance Policies, Initiatives and Uptake, the Role of Managers, and Productivity}

The role of a supportive supervisor or manager in positive outcomes for family-friendly benefits was confirmed in a large nationally representative sample study by Thompson and Prottas (2006). An earlier study by Thompson et al. (1999) found managerial support accounted for most of the explained variance in workfamily culture, ahead of negative career consequences and organizational time demands. This earlier, less representative, study also found that work-family culture was positively related to employees' use of work-family benefits and affective commitment to their work, and negatively related to work-family conflict and intentions to leave an organisation.

Bardoel (2003) investigated the relative roles of managerial factors versus institutional and resource dependent factors in explaining employer provision of work-family programmes and an accommodating workplace culture in Australia, and found that managerial factors accounted for most of the variance. Perceived benefits/efficiency gains was related to high number of work-family initiatives being offered. Managers' attitudes and strategies were related to overall number of initiatives offered. Institutional forces or policies of large or public sector organizations added to rather than drove decisions re work-family implementation. Individual managers drove the outcome.

Institutional factors had more influence on the workplace culture being accommodating of work-family programmes. Bloom et al. (2003) reviewed 732 manufacturing organizations in the US, France, the UK, and Germany to investigate the link between work-life balance and productivity. They found that there was no direct relationship between work-life balance policies/initiatives in an organization and increased productivity. Nor was there was no direct negative relationship between work-life balance and productivity. The intermediary factor was managers: good management was linked to both work-life balance policies and higher productivity. This suggests that good management is the key to work-life balance policies translating into positive outcomes such as increased productivity. This study did not investigate implementation of work-life policies.

O'Driscoll et al. (2003) in a study of 355 managers in New Zealand found perceptions of an organization having a family supportive culture and a supportive supervisor were significantly related to reduced work to home interference, but only the supportive supervisor also reduced home to work interference. Just having a worklife policy or initiatives was not related to reduction in psychological stress from conflict between work and home.
White et al found that the ability of supervisors to influence negative job to home spillover increased between 1992 and 2000.

According to De Cieri et al. (2002), the main barriers to implementation and management of work-life balance strategies identified in existing literature include organizational culture and attitudes and resistance of supervisors and middle management. In an analysis of three surveys of Australian organizations from 1997 to 2000 , they found the main barriers to implementation and management of work-life balance strategies included inaction by both senior and line managers and unsupportive culture. In particular De Cieri et al. found that uptake of work-life provisions was positively related to the number of provisions available, but there was a lag between provision and uptake. The authors note that this supports other research that found "an organizational culture that is unsupportive of work-life strategies may lead to employee reluctance to utilize benefits" (De Cieri, 2002:5).

These findings are consistent with a body of evidence that shows work-life balance and diversity policies do not in themselves produce better outcomes; that they need to be implemented through a linked series of strategies that create a supportive culture through integration into the organisations' core business strategies and through management accountability for outcomes (Managing Work/Life Balance, 2004; Rutherford and Ollerearnshaw, 2002; Opportunity Now, 2004). Without this their implementation is at the discretion of managers.

\section{Barriers to Manager Implementation of Work-Life Policies/Strategies}

Barriers to manager implementation of work-life policies/strategies identified by various studies include lack of formal written policies, resource and operational factors, lack of senior management support and a supportive workplace culture, concerns about equity among staff, traditional management styles and beliefs and a lack of training in how to manage a flexible workforce, and lack of accountability through performance measures.

A study of 806 line managers in 22 UK organizations (Opportunity Now, 2005) found they have not been convinced of the business case for gender equality/diversity, perceive a lack of support and commitment by senior management, are not being made personally accountable for achieving strategies to achieve these aims, do not feel they are being adequately trained to deal with this area, and are working long hours with poor work-life balance themselves due to heavy workloads beyond their control. This study also identified poor communication and overuse of the intranet to support and communicate with managers as a barrier to successful implementation of gender equality/diversity strategies. 
In a UK study of 1509 randomly selected workplaces. management discretion when operating work-life policies was greater where there were no formal written work-life policies (Woodland et al. 2002). Positive impact of work-life balance practices on workplace performance, as measured by employee relations with management, productivity, absenteeism, staff turnover, recruitment and employee motivation were all higher where managers followed set procedure than where they had discretion. The exception was small workplaces where employee relations were better when managers had discretion. Having a written policy was also positively related to higher up-take of flexible work practices.

Rutherford and Ollerearnshaw (2002) in a study of 140 UK organisations found making managers accountable for performance on diversity and equality outcomes to be the most important factor making this area a business priority and in achieving positive outcomes. Accountability at the individual level can involve promotion and pay. Only $32 \%$ of private sector organizations and $24^{\circ}$ of public sector organizations linked performance on diversity and equality to a manager's pay, with $48 \%$ linking to promotion, but $55 \%$ of private and $78 \%$ of public sector organizations claimed to hold them accountable. Yet $91 \%$ of those organizations linking diversity outcomes to managers' pay reported a link between diversity and their overall business performance, compared with an average of $80^{\circ}$. of all organizations in the study.

Thompson, Thomas and Maier, (1992) give four key reasons for management resistance to flexible work policies: possible inequities among staff, difficulties in prioritizing, procedural barriers and traditional management styles. Similarly, Rapaport and Bailyn (1996) and Quijada (2005) argue that managers worry about the increased workload for themselves of managing flexibility, impacts on productivity, and inequities among staff. "As a result. managers often end up sending negative signals indicating that the use of flexible, familyfriendly benefits is a problem for them and for the company as a whole" (Rapoport and Bailyn, 1996:19). Yet a US study of managers of employees who are working flexibly found $75 \%$ of these managers reported no change in their workload and almost all reported a positive impact on productivity. retention and quality of work (Boston College Centre for Work and Family, 2000:3). Another study found that managing flexible schedules has improved overall management skills (Catalyst, 2000).

Bond et al (2002) investigated the pressures, constraints and criteria that influenced decision-making of line managers who had diseretionary power for the implementation of family-friendly policies in four case study organisations. The discretionary power of line managers within a broad framework is justified by the need to tailor initiatives to individual circumstances together with the need to weight up resource and operational factors. The downside is potential inequities in the implementation of policies, either between managers or among employees. Managers in Bond et al's study were afraid more formalized policies would lead to entitlement and abuse, consistent with the lack of trust by mangers found in a New Zealand survey in New Zealand (Sweeney Research, 2004). Managers' perceptions of employee inputs and managers' attitudes to atypical working patterns were important influences on decisionmaking. Managerial attitudes to flexible working influenced employee access to such practices. In one organization Bond et al found that those managers that were least receptive to flexible working held beliefs that business objectives could only be achieved by traditional full-time work patterns. Men were more likely than women to be refused access to flexible working arrangements.

Research by Quijada (2005) among US software engineers identified trust and a focus on results as distinguishing characteristics of managers in "successfully flexible organizations". "What matters most is getting the work done", breaking from the assumption "that time equals commitment and performance. Successful managers of flexible work arrangements focus on the work, not on the hours worked. This is a very different assumption to work under, and one that dramatically makes it easier to have flexible schedules. This principle shifts the focus of the manager towards the tangible results of work as a measure of performance. Working in an organization where this principle is present results in increased responsiblity over the employees using the flexible schedules. Employees must realize that what they do impacts other members of the team and that they need to get their work done as expected, and when that is not possible they need to communicate with the team. A focus on results gives freedom to employees and mangers from the bane of face time that plagues many organizations" (Quijada, 2005:10). Quijada sets out a comparison of traditional management styles which she calls "line of sight" style, with "target based styles" more suited to flexible work practices. Managing a flexible workplace requires careful planning, clear and frequent deliverables, core hours, leveraging of technology, and shifting responsibility for making work happen on to employees.

Two areas of constraint in granting flexible work options identified by Bond et al were where skills cannot easily be substituted, and where there are time constraints. However local research by Sweeney Research shows even where these factors were not present, managers were reluctant to manage a flexible workforce.

Yeandle et al 2003 UK interviewed 100 managers in 30 workplaces and found they do not have adequate training for dealing with requests from employees for work-life initiatives such as flexible working arrangements.

\section{What New Zealand Managers are or are not Doing}

The first EEO Trust Work-Life Survey was completed by 462 organisations covering 262,878 workers during MayJune 2006. The survey was sent to 362 members of the EEO Trust Employers' Group, and approximately 3000 other organizations. Responses were received from 326 
EEO members, and 136 other organizations. The majority had 10 or more staff and results below are from this group. Data from the 51 organisations with fewer than 10 staff were analysed separately (EEO Trust, 2006). Those organizations who participated and who belong to the EEO Trust Employers group are likely to have more interest in work-life issues, and thus results are likely to be higher than might be expected across all New Zealand employers.

The survey focused on the path from policy/strategy, through implementation to outcomes. It measured prevalence of work-life policies/strategies, a range of work-life initiatives, and the prevalence of a set of implementation steps identified in the EEO/diversity literature and research as necessary for successful outcomes. These steps are: senior management commitment, policy integrated into core business objectives, communication throughout the organization, staff needs assessment, written action plan, training for managers in implementing and managing a flexible workforce, accountability for policy outcomes, and measurement of progress and outcomes (Managing Work/Life Balance, 2004; Rutherford and Ollerearnshaw, 2002; Opportunity Now, 2004)

Outcomes have been identified in the literature as reduced staff turnover, reduced absenteeism, and increased return rate from parental leave (Department of Labour, 2006b; Managing Work/Life Balance, 2004; Yasbek, 2004). Intermediate to this is uptake of work-life balance initiatives.

The EEO Trust Work-Life Survey indicates that New Zealand organizations are doing little beyond having a policy/strategy for work-life balance, communicating that throughout organization, and offering a range of initiatives, the most of common of which are flexible hours and domestic and special leave.

\section{Figure 1: Demonstration of senior management commitment.}

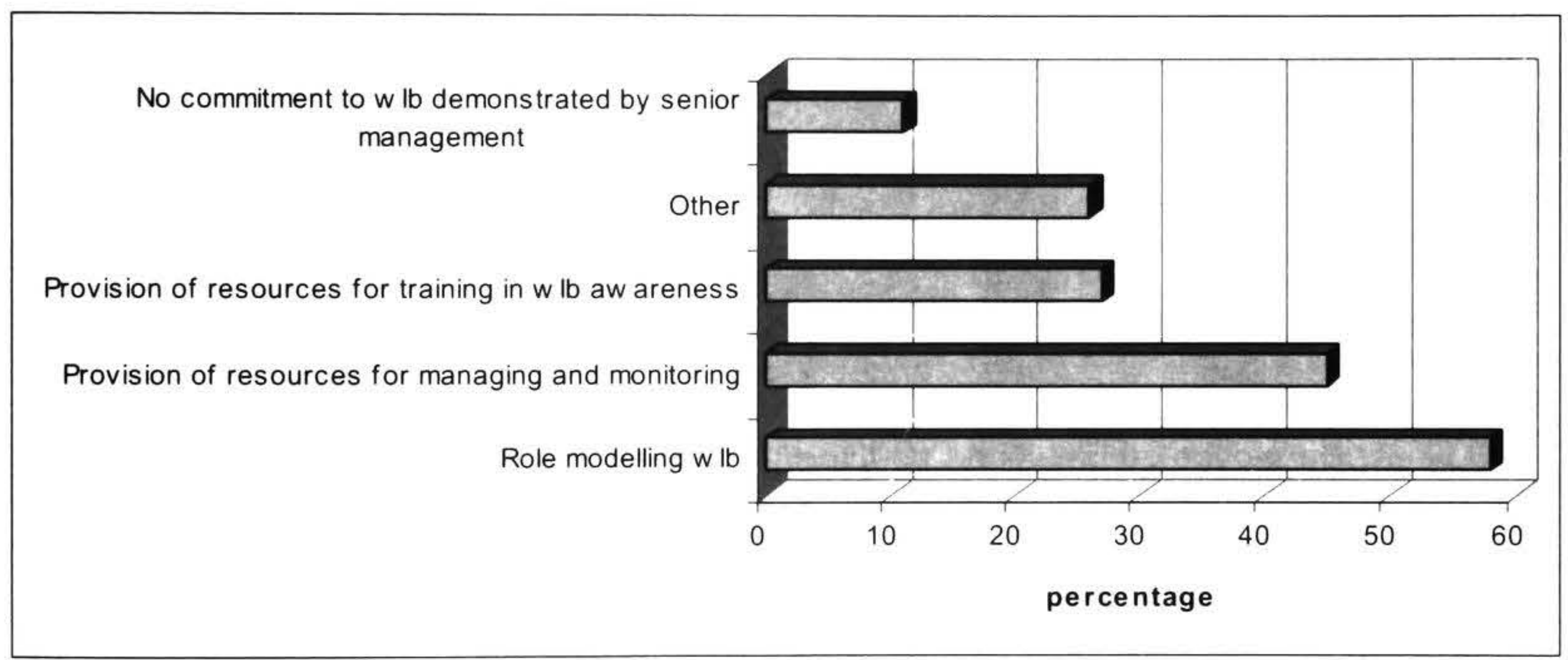

Figure 2: Implementation of work-life balance policy or strategy.

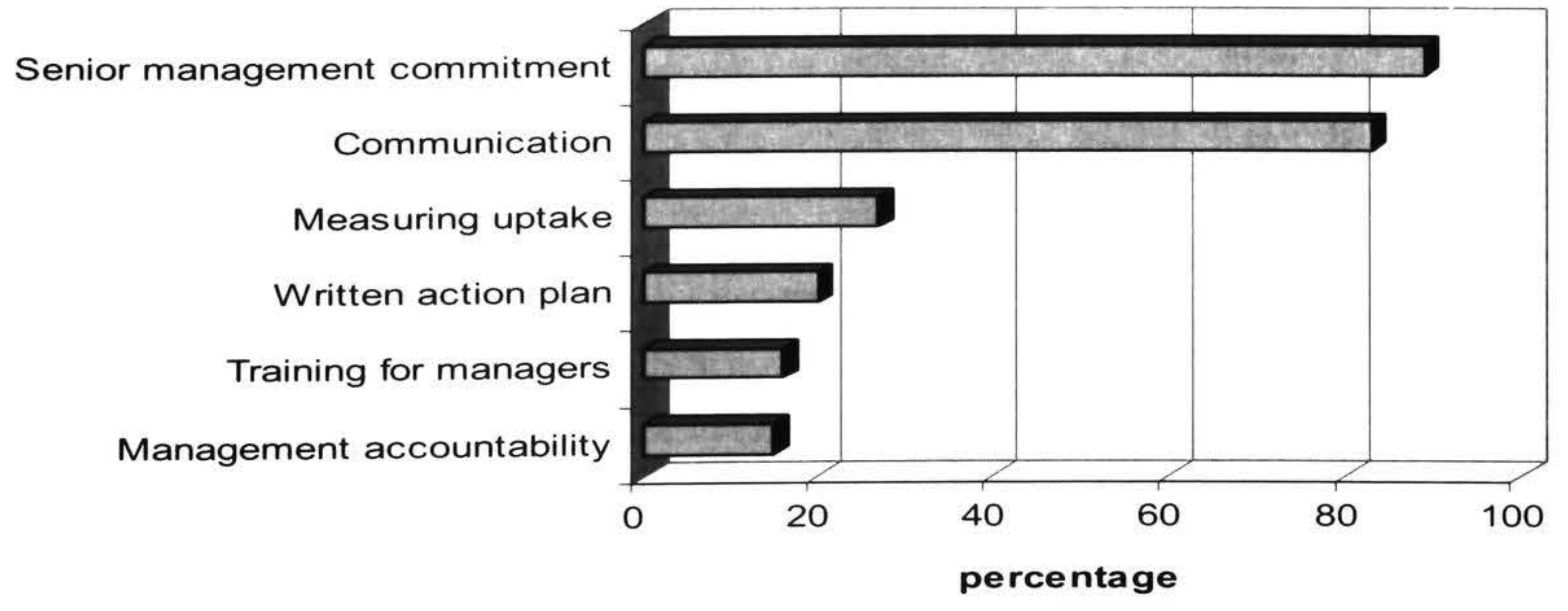


While senior management commitment is reported as being strong, this is demonstrated mainly by role modelling, followed by providing resources for managing and monitoring progress (Figure 1).

There is little training for managers in the implementation and management of work-life balance policies and initiatives $(16 \%)$, or accountability for work-life balance implementation and outcomes through building it into their performance reviews or contracts $(15 \%)$. In addition, few had written action plans $(20 \%)$ or were measuring uptake of work-life initiatives by staff in their organization $\left(27^{\circ}\right.$ ) (Figure 2 ).

The Hudson report $(2005: 23)$ recommends ensuring that formal policies are consistent with what employees actually experience in order to ensure policies result in better work-life balance for employees. But the EEO Trust Work-Life Survey (2006) found there was little in way of measuring staff needs in relation to work-lifebalance: only $25 \%$ specifically survey staff to find out about their work-life balance needs, and $21 \%$ to find about their awareness of work-life balance in the organization (Figure 3). In comparison $66 \%$ were conducting employee satisfaction surveys.

The EEO Trust Work-Life Survey (2006) found that organizations that had carried out the most implementation steps and offered the most initiatives were more likely to report increased uptake of work-life initiatives, reduced staff turnover, reduced absenteeism, and increased return from parental leave (Figure 4).

Figure 3: Employers attempts to measures staff work-life balance needs.

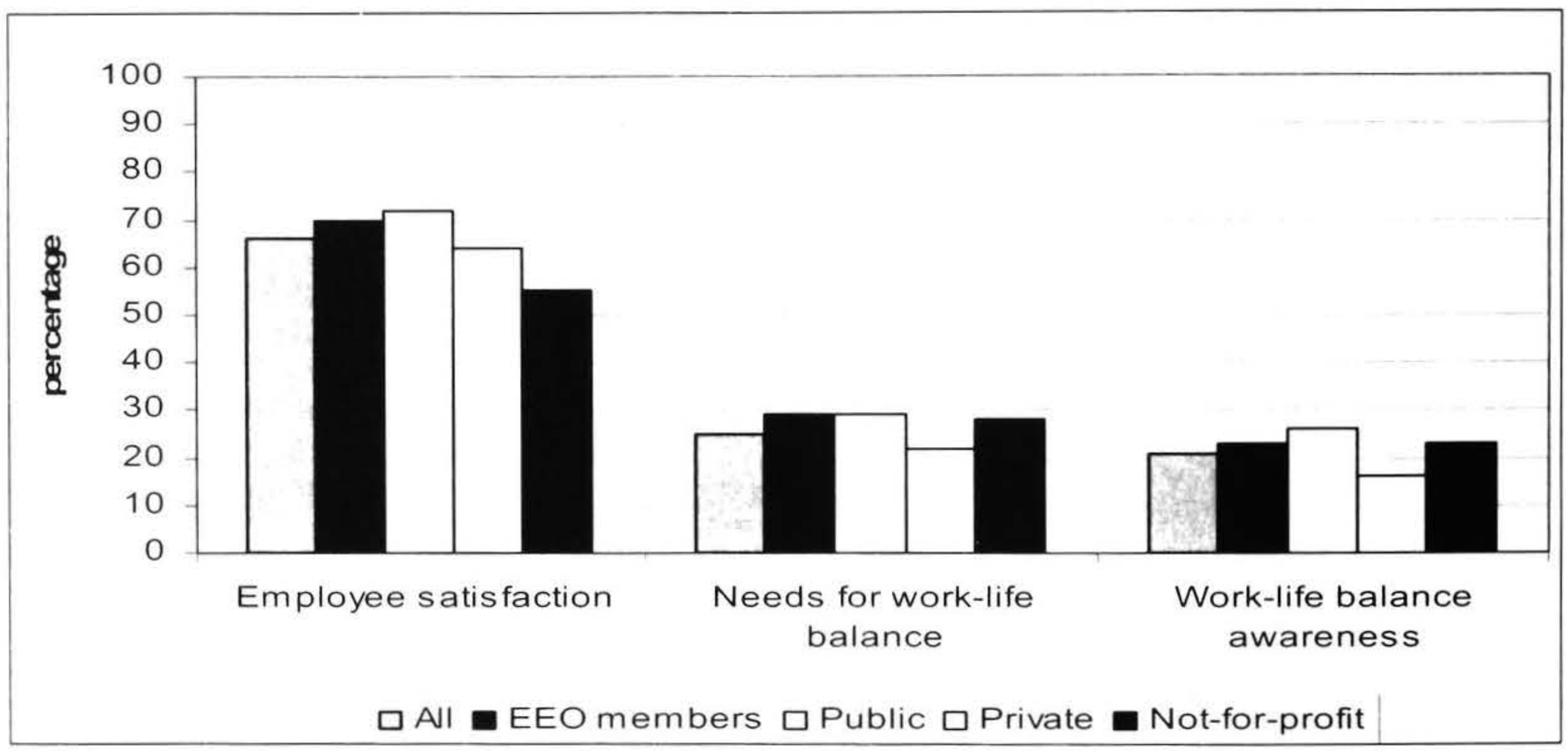

Figure 4: Best practice outcomes in last 12 months.

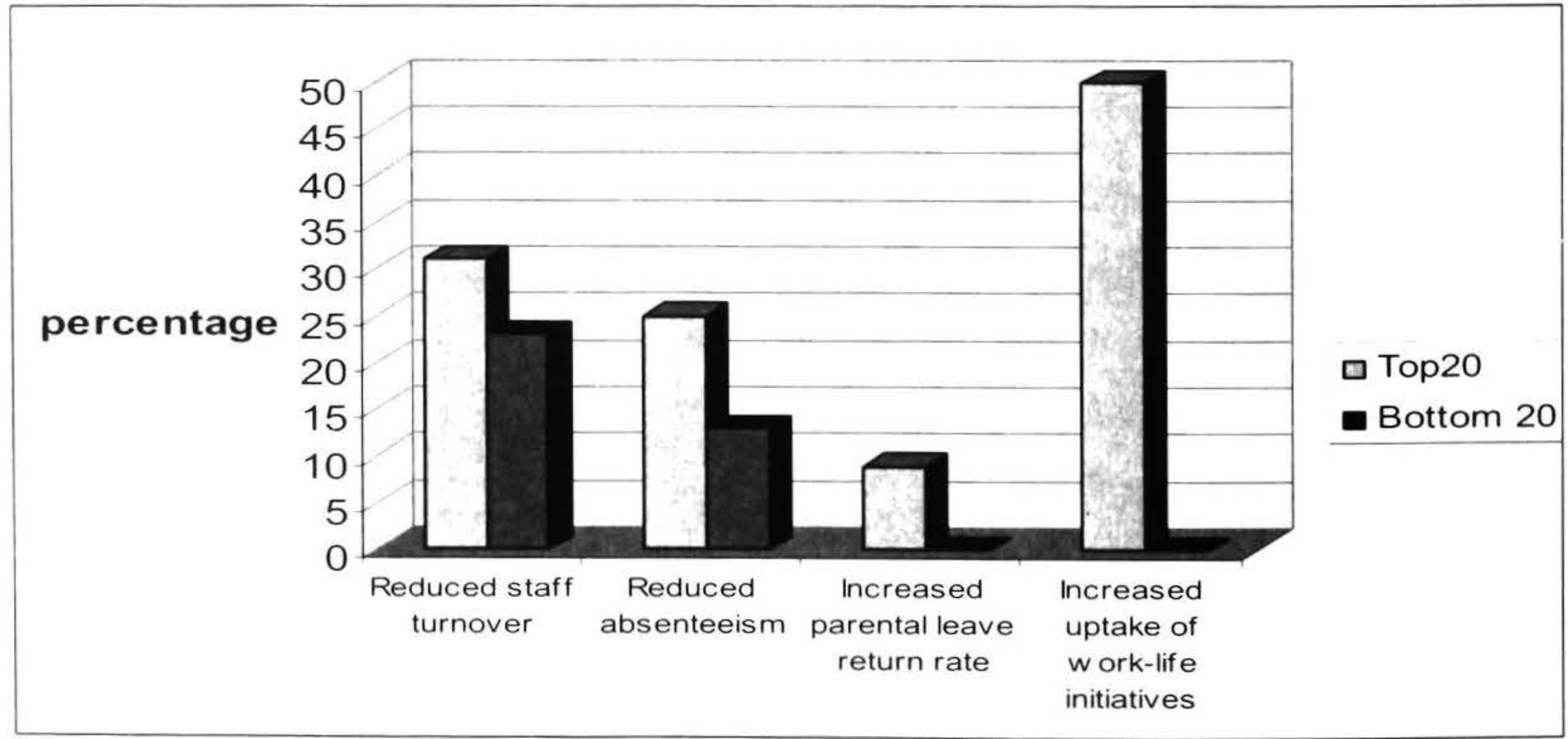


The EEO Trust survey is not a random sample survey, and the findings are likely to be skewed towards higher outcomes than might be found across all New Zealand employers. However, these findings are not inconsistent with those of Sweeney Research, who undertook a national random sample survey of NZ (198) and Australian (402) organizations in 2004. A key finding of this study was that only $35 \%$ of $\mathrm{NZ}$ organisations reported offering flexible work options, yet $39 \%$ of personnel in non-flexible workplaces have jobs that can be undertaken flexibly" (Sweeney Research, 2004:5). Three-quarters of managers in non-flexible workplaces aid they would be unlikely to allow employees to work flexibly even if the organisation allowed it, despite $47 \%$ of employees saying they would take up the option if it was available.

The main reason identified by Sweeney Research for the low rate of flexibility was management attitude. A main obstacle to flexible working found in this study was the perceived difficulty in monitoring and supervising employees who work flexibly. This was related to a climate of mistrust of flexible workers by both managers and colleagues. This is related in part to the use of old style performance appraisal practices; relying on attendance rather than performance/outputs. The researchers concluded that there is, therefore, a "need for education and training into how to manage flexible workers and a need to communicate the benefits more effectively".

A UMR (2003) qualitative study of perceptions towards work-life balance in New Zealand found that perceived barriers to implementing work-life initiatives in New Zealand were perceived cost, lack of time and resources and lack of expertise and knowledge. The 2006 Department of Labour survey of employers found that one of the main barriers was that "it's too complicated to have these types of work arrangements for employees" (Department of Labour, 2006:36).

\section{How We Compare}

An Australian study (Managing Work/Life Balance, 2004) of 294 organisations found that "best practice" organizations were more likely than other organizations to have senior management commitment, encourage a creative approach to resolving problems, link work-life issues with organizational values, communicate regularly about policies and programmes, demonstrate the business imperative for change, recognize results rather than time spent in the workplace, provided training sessions on work-life issues, link management of work-life issues with performance management and recognize and reward successful work-life management. While training and management accountability were more likely to be practiced by those organizations with better work-life balance outcomes, they were less likely to be practiced than the other implementation strategies listed.

A UK study of gender equity found that only $26 \%$ of employers were including progress on gender equality/diversity in managers' performance goals
(Opportunity Now 2005). Only 66\% of employers in this study believed they have middle management commitment, compared with $81 \%$ who report having senior management commitment.

Another UK study involving case studies of the role and perspectives of 91 line managers in four organisations(Yeandle et al. 2003) found lack of training and support for line managers to be a major impediment to implementation of family-friendly policies.

\section{Employees' Perspectives}

The Department of Labour (2004) work-life balance project found both employers and employees acknowledged management support as a vital aspect of work-life balance provisions, and that individual managers' and supervisors' attitudes can have a great deal of influence on outcomes for employees.

The more recent Department of Labour survey of New Zealand employees (2006:39) found a clear link between comfort discussing work-life issues with management and overall work-life balance, and between positive workplace culture and work-life balance, where positive workplace culture included lack of negative impact on career and lack of resentment by fellow workers. Almost $60 \%$ of employees in this survey said that aspects of their workplace culture made work-life balance harder to achieve, particularly expectations of colleagues, managers and supervisors. (Department of Labour, 2006: 7).

Consistent with these findings, a theme emerging from a qualitative study of forty mothers in paid work was that manager attitude and discretion was a key factor in whether work-life policies are actually implemented (McPherson, 2006).

I work for a very large organisation and I do know those are their policies. I am vern fortunate to work for a manager who works within those policies and is happy with those policies and gemuinely doesn t mind. I know for a fact that it's not the case with all managers and that mine's probably the exception rather than the rule in that regard.

\section{Conclusions}

There is evidence that New Zealand organisations that offer more work-life provisions and implement more work-life steps achieve better outcomes, as for their overseas counterparts. It appears that most New Zealand organisations have not moved sufficiently along the implementation pathway to include training and accountability for managers, or to measure needs and outcomes. In this we are similar to Australia. New Zealand organizations, at least those with an interest in work-life balance issues as a way to attract and retain staff and improve productivity, have so far concentrated on developing policies, and to a lesser extent making the 
business case and getting senior management commitment. The next step is to translate that into implementation by developing written action plans and management accountability for realizing those plans. This requires training and support for managers in managing a flexible workforce, and resourcing for the collection of data to monitor progress and outcomes of the implementation plan.

\section{Recommendations - How to Improve Outcomes from Work-Life Initiatives by Attention to the Role of Managers/Workplace Culture}

\section{Training and Support}

The New Zealand Department of Labour report (2004:41) recommended improvements to the quality of employer and management support and training in work-life balance area. The UK gender equity organization Opportunity Now (2005:56) recommends developing a toolkit for managers which lays out the basic skills and knowledge which they need to successfully implement flexible working. For example, setting goals and objectives, monitoring progress and measuring success, redesigning work, managing team dynamics in a flexible workforce, maintaining and improving team communication, managing performance and career planning. and providing a demonstrated business case for flexible working. This should be followed up with support for managers managing teams that are working in new and diverse ways.

\section{Accoumtahiliț}

Managers should be made accountable for achieving work-life balance goals and objectives which are linked to core business objectives. This can be done by linking performance appraisal, pay and promotion to achievements on the written work-life strategy action plan.

\footnotetext{
"The ability to manage flexible teams should be a management competency, reflected in your performance system" (Opportunity Now. 2006:56).
}

\section{Resoluring}

Resourcing need to be made available for the implementation and measurement of progress and outcomes on the written work-life action plan. This includes resourcing for training managers and communicating strategies and plans, rationale and objectives to all staff.

\section{Creating a Culture of fcceptance and Encouragement}

Starts with making the business case to senior management to get their commitment and leadership through role modeling. resourcing and supporting other managers to implement the work-life strategy. Focus then needs to shift to communication of business objectives, training, support and accountability for line mangers and supervisors. Finally, putting the work-life strategy into practice through a written action plan, which includes an assessment of the work-life needs of staff in a particular organization or local branch, and monitoring of progress and outcomes.

\section{Note}

I Best practice organizations are identified as those in the top quartile of a score calculated on the basis of work-life balance programmes and policies offered in their organization.

\section{References}

Bardoel, E.A., (2003). The provision of formal and informal work-family practices: The relative importance of institutional and resource dependent explanations versus managerial explanations. Women in Management Review, 18(1/2), pp.7-19.

Bloom, N., Kretschmer, T. and van Reenen, J. (2006). Work life balance, management practices and productivity. Centre for Economic Performance, London School of Economics. www.Ise.ac.uk

Bond, S. (2004). Organizational culture and work-life conflict in the UK. International Journal of Sociology and Social Policy, 24(12):1-23

Bond, S., Hyman, J., Summers, J. and Wise, S. (2002). Family Friendly Working? Putting Policy into Practice. Joseph Rowntree Foundation, YPS, York.

Boston College Center for Work and Family (2000). Measuring the Impact of Workplace Flexibility. Chestnut Hill: Boston College Center for Work and Family.

Catalyst inc. (2000). Flexible work arrangements III: A Ten-Year Retrospective of Part-Time Arrangements for Managers and Professionals. New York: Catalyst.

De Cieri, H., Holmes, B., Abbott, J. and Pettit, T. (2002). Work/Life Balance Strategies: Progress and Prohlems in Australian Organisations. Working Paper 58/02. Dept of Management, Monash University.

Department of Labour (2006a). Work-Life Balance in New Zealand. A Snapshot of Employee and Employer Attitudes and Experiences. www.dol.govt.nz

Department of Labour (2006b). Quality Flexible Working Arrangements. How Workplaces Describe the Benefits. Workplace Leaders' Summit, 2006. www.dol.govt.nz 
Department of Labour (2004). Achieving Balanced Lives and Employment. What New Zealanders are Saying About Work-Life Balance. www.dol.govt.nz

EEO Trust (2006). Work-Life Survey. Auckland: Equal Employment Opportunities Trust. www.eeotrust.org.nz

Hudson (2005). The Case for Work/Life Balance: Closing the Gap between Policy and Practice. Hudson Australia and New Zealand, www.hudson.com

Managing Work Life Balance (2004). Work/Life Initiatives: The Way Ahead Report on the Year 2004 Survey. www.worklifebalnce.com.au

McDonald, P., Brown, K. and Bradley, L. (2005). Explanations for the provision-utilisation gap in work-life policy. Women in Management Review, 20(1), 37-55.

McPherson, M. (2006). New Zealand Cultural Norms of Parenting and Childcare and how these Relate to Labour Force Participation Decisions and Requirements. Report of Qualitative Interviews with 40 Mothers. Families Commission, Wellington.

McPherson, M. and Reed, P. (2007 in press). WorkLife Balance in the New Zealand Context.

O'Driscoll, M., Poelmans, S., Spector, P., Kalliath, T., Allen, T., Cooper, C. and Sanchez, J. Familyresponsive interventions, perceived organizational and supervisor support, work-family conflict, and psychological strain. International Journal of Stress Management. 10(4), 326-344.

Opportunity Now (2005). Line Managers and Diversity: Making it Real.

www.opportunitynow@bitc.org.uk

Opportunity Now (2004). Diversity Dimensions Integration into Organizational Culture. www.opportunitynow@bitc.org.uk

Quijada, M.A. (2005). Managing Flexible Schedules: What Successful Organizations Do. Working Paper No. WPC0023, MIT Workplace Center. Web.mit.edu/workplacecenter

Rapoport, R. and Bailyn, L. (1996). Relinking Life and Work: Toward a Better Future. Ford Foundation.

Rutherford, S. and Ollerearnshaw, S. (2002). The Business of Diversity. How Organizations in the Public and Private Sectors are Intergrating Equality and Diversity to Enhance Business Performance. Scheider-Ross, Andover, Hants. www.sdchneiderpross.com
Stevens, J., Brown, J. and Lee, C. (2004). The Second Work-Life Balance Study: Results from the Employees' Survey. Department of Trade and Industry, www.dti.gov.uk/publications

Sweeney Research, (2004). Mobility and Mistrust. An Independent Research Report Commissioned by Toshiba Australia Information Systems Division into the Attitudes of Managers and Employees in Australia and New Zealand Towards Flexible Working. www.isd.toshiba.com.au

Thompson, C., Beauvais, L. and Lyness, K. (1999). When work-family benefits are not enough: the influence of work-family culture on benefit utilization, organizational attachment and workfamily conflict. Journal of Vocational Behavior, 54, 392-415.

Thompson, C., Thomas, C., and Maier, M. (1992). Work-family conflict: reassessing corporate policies and initiatives. In Sekara, U. and Leong, F. (eds) Womanpower. Managing in Times of Demographic Turbulence. Sage.59-84.

UMR (2003). Perceptions and Attitudes Towards WorkLife Balance in New Zealand: A Qualitative Study. www.umr.co.nz

White, M., Hill, S., McGovern, P., Mills, C. and Smeaton, D. (2003). High-performance management practices, working hours and worklife balance. British Journal of Industrial Relations, 41:2, pp.175-195.

Woodland, S., Simmonds, N., Thornby, M., Fitzgerald, R. and McGee, A. (2003). The second work-life balance study: results from the employer survey - main report. Department of Trade and Industry, www.dti.gov.uk/publications

Yasbek, P. (2004). The business case for firm-level work-life balance policies: a review of the literature. Department of Labour, Wellington. www.dol.govt.nz

Yeandle, S., Phillips, J., Scheibl, F., Wigfield, A. and Wise, S. (2003). Line Managers and FamilyFriendly Employment. Roles and Perspectives. Policy Press, Bristol.

\section{Author}

Mervyl McPherson

Researcher

Equal Employment Opportunities Trust

P.O. Box 12929

Auckland

mmcpherson@eeotrust.org.nz 